\title{
Dynamic assessment of direct-current mobility in field-assisted sintered oxide dispersion-strengthened $\mathrm{V}-4 \mathrm{Cr}-4 \mathrm{Ti}$ alloys
}

\author{
Vinoadh Kumar Krishnan ${ }^{*}$ and Kumaran Sinnaeruvadi
}

\begin{abstract}
Background: Vanadium alloy is one of the potential candidate material for structural applications in a commercial fusion reactor. Extended survival of a structural material has a direct consequence on the net energy produced in a fusion reaction, it is important to develop ultra-functional materials with tailored microstructures, to meet the harsh fusion environments. Microstructure of material, indeed depend upon the thermodynamics and kinetics of material processing.
\end{abstract}

Methods: Aiming to meet the harsh fusion conditions, we have developed oxide dispersion strengthened $\mathrm{V}-4 \mathrm{Cr}-4 \mathrm{Ti}$ alloys by high energy ball milling and field assisted sintering technique. Possible microstructural, morphological aftermaths observed in ball milled yttria dispersed V-4Cr-4Ti powders is explored.

Results and conclusion: Electron microscopy and laser particle analysis acknowledge that yttria addition aids powder agglomeration during ball milling. Ball milled powder was then consolidated (to a relative density of $\sim 100 \%$ ) using field assisted sintering technique, under optimal sintering conditions. Densification profile has implied that heterogeneous powder characteristic (apparent particle size and shape of powder) tends to impede the directcurrent conductivity across the powder particle during various stages of field assisted sintering. In order to understand the kinetics of the field assisted sintering process on the starting powders, a new method was developed to compute the activation energy required for the direct-current conductivity across the individual powder particles. Relatively higher activation energy (for direct-current conductivity) is required for sintering yttria dispersed V-4Cr-4Ti powder than its V-4Cr-4Ti counterpart.

Keywords: Vanadium, Yttria, Milling, Sintering, Densification, Activation energy

\section{Background}

Paybacks of $\mathrm{V}-4 \mathrm{Cr}-4 \mathrm{Ti}$ alloy as a candidate material in fusion power generation has been extensively discussed elsewhere (Zinkle et al. 2008; Smith et al. 1996; Johnson and Smith 1998; Smith et al. 1995; Muroga et al. 2002). $\mathrm{V}-4 \mathrm{Cr}-4 \mathrm{Ti}$ alloys have been relentlessly proving themselves as a potential alternative to basic steels and oxide dispersion-strengthened steels owing to their superior performance as a structural material like high temperature mechanical properties, irradiation resistance at elevated temperatures $\left(>400{ }^{\circ} \mathrm{C}\right)$, low activation under fast neutron flux, and high ductility (Chung et al. 1996; Rice and Zinkle

\footnotetext{
* Correspondence: vinoadhkumarkrish@gmail.com

Department of Metallurgical and Materials Engineering, National Institute of Technology, Tiruchirappalli, Tamil Nadu 620015, India
}

1998; Gelles 1998). Even though the microstructural stability of $\mathrm{V}-4 \mathrm{Cr}-4 \mathrm{Ti}$ alloys at elevated temperature $\left(>650{ }^{\circ} \mathrm{C}\right)$ is superior to ferritic/martensitic steels, the anticipated power conversion efficiencies expected out of plasma-facing components have increased tremendously (Loomis et al. 1994). This intrigued fusion scientists to look for an ultra-functional $\mathrm{V}-4 \mathrm{Cr}-4 \mathrm{Ti}$ alloy to withstand harsh conditions inside the fusion reactor, consequently enhancing the power generation efficiency of the same. One such work was attempted in the year 1996, by dispersing ultrafine yttria particles in V-4Cr-4Ti alloy (Yamagata et al. 1996). Shibayama and his coworkers developed the oxide dispersion strengthened (ODS) vanadium alloy by a novel powder metallurgy route, namely mechanical-alloying (MA) (Suryanarayana 
and Norton 1999; Alamo et al. 1992; Miller et al. 2005; Miller et al. 2003; Plant and Steel 1995). Earlier reports have consolidated ODS vanadium alloys using the hot isostatic pressing (HIP) technique, while a recent report suggests that field-assisted sintering (FAST) or spark plasma sintering (SPS) technique offers a variety of microstructural merits that can enhance the high temperature mechanical properties of $\mathrm{V}-4 \mathrm{Cr}-4 \mathrm{Ti}$ alloys (Krishnan and Sinnaeruvadi 2016). Vital merits offered by the FAST process include self-cleaning of the oxide layer in powder particles before sinter-bonding, retaining the nanostructure, and consolidating the powder particle to full density within a short span of time at lower temperature regimes (Mamedov 2000; Aalund 2008; Yucheng and Zhengyi 2002; Anselmi-tamburini et al. 2005; Chen et al. 2005). But no single literature is available to explain the densification mechanism behind sintering (FAST) V$4 \mathrm{Cr}-4 \mathrm{Ti}$ and yttria-dispersed $\mathrm{V}-4 \mathrm{Cr}-4 \mathrm{Ti}$ powders. Once the densification mechanism and its associated kinetics behind FAST-processing of the $\mathrm{V}-4 \mathrm{Cr}-4 \mathrm{Ti}$ powders are understood, tailoring the material properties via FAST process to match fusion-relevant conditions become conceivable (Tong et al. 2009; Thornton 1999; Thornton et al. 2004; Iimura et al. 2009; Yu et al. 1997).

In the present investigation, variations in current consumption while sintering $\mathrm{V}-4 \mathrm{Cr}-4 \mathrm{Ti}$ and yttriadispersed $\mathrm{V}-4 \mathrm{Cr}-4 \mathrm{Ti}$ powders are discussed briefly. Further, the DC (direct-current) conductivity profile while sintering powder was obtained in order to understand the effect of yttria addition on the microstructural and morphological characteristics of ball-milled powders. Finally, the activation energy $\left(E_{\mathrm{a}}\right)$ required for the sintering current to traverse through the individual powders was deduced.

\section{Methods}

\section{Powder preparation}

Elemental powders of vanadium, titanium, and chromium with a purity of $99.9 \%$ and particle size equivalent of -325 mesh size were ball-milled using Retsch, PM-400 planetary ball mill. The typical ball-milling conditions

Table 1 Ball-milling conditions employed for synthesizing $\mathrm{V}-4 \mathrm{Cr}-4 \mathrm{Ti}$ and yttria-dispersed $\mathrm{V}-4 \mathrm{Cr}-4 \mathrm{Ti}$ powders

\begin{tabular}{ll}
\hline Variables & Conditions \\
\hline Type of ball mill & High-energy planetary ball mill \\
Milling vessel and media & Tungsten carbide (WC) \\
Plate rotation & $250 \mathrm{rpm}$ \\
Milling time & $10 \mathrm{~h}$ \\
Ball-to-powder ratio & $10: 1$ \\
Ball-milling atmosphere & $\mathrm{High}$ purity argon (99.99\% pure) \\
Surfactant & $\mathrm{NaCl}$ \\
\hline
\end{tabular}

used for synthesizing $\mathrm{V}-4 \mathrm{Cr}-4 \mathrm{Ti}$ and nano-yttriadispersed V-4Cr-4Ti powders are presented in Table 1. Ascribed powders in the aforementioned atomic proportions were transferred into tungsten carbide (WC) vials inside the glove box under high pure argon environment (99.99\% pure).

\section{Powder characterization}

Powder morphology, apparent particle size, and chemical composition of ball-milled $\mathrm{V}-4 \mathrm{Cr}-4 \mathrm{Ti}$ and yttriadispersed $\mathrm{V}-4 \mathrm{Cr}-4 \mathrm{Ti}$ powders were studied with the help of scanning electron microscopy images accompanied with energy-dispersive absorptive X-ray spectroscopy (SEM-EDAX). The milled powders were dispersed in ethanol and ultrasonicated for $120 \mathrm{~s}$. The sonicated powders were transferred onto a glass plate and dried in air; subsequently, the powder was transferred onto a carbon tape placed over an aluminum stub and maintained under vacuum $24 \mathrm{~h}$ prior to electron microscopy-imaging. From the electron microscopy images, quantitative estimates of apparent particle size $(\mu \mathrm{m})$ were calculated using ImageJ (version 1.50b) software. Further, to confirm the apparent particle size and its distribution, laser particle size analysis was carried out using Mastersizer 3000 laser diffraction particle size analyzer (Malvern Instruments, UK).

\section{Field-assisted sintering}

Ball-milled powders were transferred into the graphite die-punch setup inside the glove box maintained under high pure argon (99.99\%) environment. Subsequently, the powder was sintered at $1100{ }^{\circ} \mathrm{C}$ for 20 min with a uniaxial pressure of $40 \mathrm{MPa}$. The relative density of FAST-processed samples was calculated using Archimedes principle. Auxiliary data (recorded every $5 \mathrm{~s}$ ) with information containing voltage, current, temperature, vacuum, and displacement were recorded during the process. From the auxiliary data, electrical resistivity and conductivity values were computed from the fundamental equations as follows:

$$
R=\rho\left(\frac{l}{A}\right)
$$

where $R$ is the electrical resistance in ohms calculated from the auxiliary data generated by FAST, $\rho$ is the electrical resistivity in ohm-meter offered by the ball-milled powders during sintering, $l$ is the dynamic sample thickness (linear shrinkage) in millimeter, and $A$ is the crosssectional area of the sample in square millimeters. Using the dynamic electrical resistivity $(\rho)$ value calculated from Eq. (1), dynamic electrical conductivity $\sigma$ in mho per meter was calculated from the following equation: 


$$
\sigma=\frac{1}{\rho}
$$

In order to evaluate the rate constant of a chemical reaction on an absolute scale (Kelvin, K), the Arrhenius equation was used to calculate the activation energy for DC conductivity while sintering ball-milled $\mathrm{V}-4 \mathrm{Cr}-4 \mathrm{Ti}$ and yttria-dispersed $\mathrm{V}-4 \mathrm{Cr}-4 \mathrm{Ti}$ powders. The typical Arrhenius equation that was used to plot and compute the activation energy profiles is mentioned below:

$$
\sigma=A \exp \left(\frac{E_{\mathrm{a}}}{K_{\mathrm{b}} T}\right)
$$

where, $A$ is the pre-exponential factor, $E_{\mathrm{a}}$ is the experimental activation in joules, $K_{\mathrm{b}}$ is Boltzmann's constant $\left(1.3806 \times 10^{-22} \mathrm{~J} \mathrm{~K}^{-1}\right)$, and $T$ is the absolute temperature in Kelvin. Mathematically, the slope value from the Arrhenius plot is calculated based on the following equation:

$$
\ln (\sigma)=\ln (A)+\text { slope. }\left(\frac{1}{T}\right)
$$

The slope value computed by plotting $\ln \left(\sigma_{\mathrm{dc}}\right)$ in the abscissa and $\Delta(1 / T)$ in the ordinate is principally used to calculate the activation energy $\left(E_{\mathrm{a}}\right)$ for DC conductivity as shown below:

$$
E_{\mathrm{a}}=-K_{\mathrm{b}} \times \text { slope }
$$

\section{Results and discussion}

Electron microscopy images accompanied with energydispersive absorptive spectroscopy (SEM-EDAX) patterns of unmilled (Fig. 1a), milled (Fig. 1b), and yttria-dispersed (Fig. 1c-e) V-4Cr-4Ti powders are presented in Fig. 1. The unmilled powders exhibit irregular shape with an apparent particle size of $\sim 40 \mu \mathrm{m}$. The milled powder has resulted in a narrow particle size distribution with an apparent particle size of $\sim 8 \mu \mathrm{m}$ (Fig. 1b). A steady increment in the apparent particle size with increasing $\mathrm{Y}_{2} \mathrm{O}_{3}$ content is noticed. Most importantly, the addition of nano-yttria in the $\mathrm{V}-4 \mathrm{Cr}-4 \mathrm{Ti}$ powder must have catalyzed the fracturing phenomenon during ball-milling. Upon reaching the limit of comminution, due to very high surface energy, the powder particles must have agglomerated, resulting in a relatively broader apparent particle size distribution. The typical apparent particle sizes of ball-milled powders corresponding to $0.3,0.6$, and 0.9 at.\% yttria additions are $\sim 14, \sim 19$, and $\sim 24 \mu \mathrm{m}$, respectively (Fig. 1c-e). The apparent particle size $(\sim 8 \mu \mathrm{m})$ and homogenous shape distribution in the ball-milled $\mathrm{V}-4 \mathrm{Cr}-4 \mathrm{Ti}$ powders (Fig. 1b) endorse the balance between fracturing and coldwelding phenomena during milling ( $\mathrm{Yu}$ and Standish 1993). For ball-milling V-4Cr-4Ti powders with varying nano-yttria content, the exponential supremacy of coldwelding (Fig. 1c-e) is evident leading to the agglomeration of powders. Thus, yttria addition could have possibly suppressed the role of a surfactant $(\mathrm{NaCl})$ during ball-milling, leading to excessive cold-welding and the subsequent agglomeration of powders. The EDAX spectra corresponding to the unmilled and milled $\mathrm{V}-4 \mathrm{Cr}-4 \mathrm{Ti}$ powders reveal the presence of $\mathrm{Na}$ and $\mathrm{Cl}$ content (Fig. 1b) while the EDAX spectra representing the nano-yttria-dispersed powder show the absence of $\mathrm{Na}$ and $\mathrm{Cl}$ spectra (Fig. 1c-e). The absence of $\mathrm{Na}$ and $\mathrm{Cl}$ spectra in the EDAX patterns (Fig. 1c-e) principally confirms the due absence of $\mathrm{NaCl}$ 's role as a surfactant/lubricant in the later stages of ball-milling. The absence of surfaceactive agents $(\mathrm{NaCl})$ must have ramped up the surface tension of powder particles during milling, thereby promoting powder agglomeration (Adams 1994; Mills et al. 2000; Mullier et al. 1991).

Typical outcomes corresponding to the laser particle analysis of $\mathrm{V}-4 \mathrm{Cr}-4 \mathrm{Ti}$ powders with varying yttria content are presented in Fig. 2 and Table 2. Upon ball-milling, substantial size reduction in the powders is evident and the same can be inferred from the left-sided shift and relatively narrow size distribution profile. Most importantly, while ball-milling the nano-yttria-dispersed $\mathrm{V}-4 \mathrm{Cr}-4 \mathrm{Ti}$ powders, significant right-sided shift and steady growth in the width of the distribution profile can be observed. Both right-sided shift and growth in the size distribution profile (with yttria addition in the $\mathrm{V}-4 \mathrm{Cr}-4 \mathrm{Ti}$ powders) approve the clustering or agglomeration of powder particles during milling (Fig. 2 and Table 2). As a point of mention, sintering of powders with a relatively broader particle size distribution can yield relatively dense compacts (close to theoretical density) for a less total linear shrinkage. Ascribed discussion pertaining to the agglomeration of powders with yttria addition strongly concedes with the electron microscopy studies.

Figure 3 reveals the DC conductivity profiles deduced from the auxiliary data generated by the FAST apparatus. DC conductivity profiles clearly demonstrate that yttria addition in the $\mathrm{V}-4 \mathrm{Cr}-4 \mathrm{Ti}$ powder suppresses the current conductivity across the individual powder particles. Increase in the electrical resistance with varying yttria content can be inferred from the upward shift in the DC conductivity profiles as a function of sintering temperature. Gradual agglomeration of powders and growing complexity in the particle morphology with yttria addition should be the possible reasons behind the upward shift in the DC conductivity profiles.

The activation energy values computed from the DC conductivity profile is shown in Fig. 4. Yttria addition clearly shoots up the $E_{\mathrm{a}}$ values for current conduction (DC conductivity) across the powder particles during FAST-processing. The gradual increment in the $E_{\mathrm{a}}$ values 


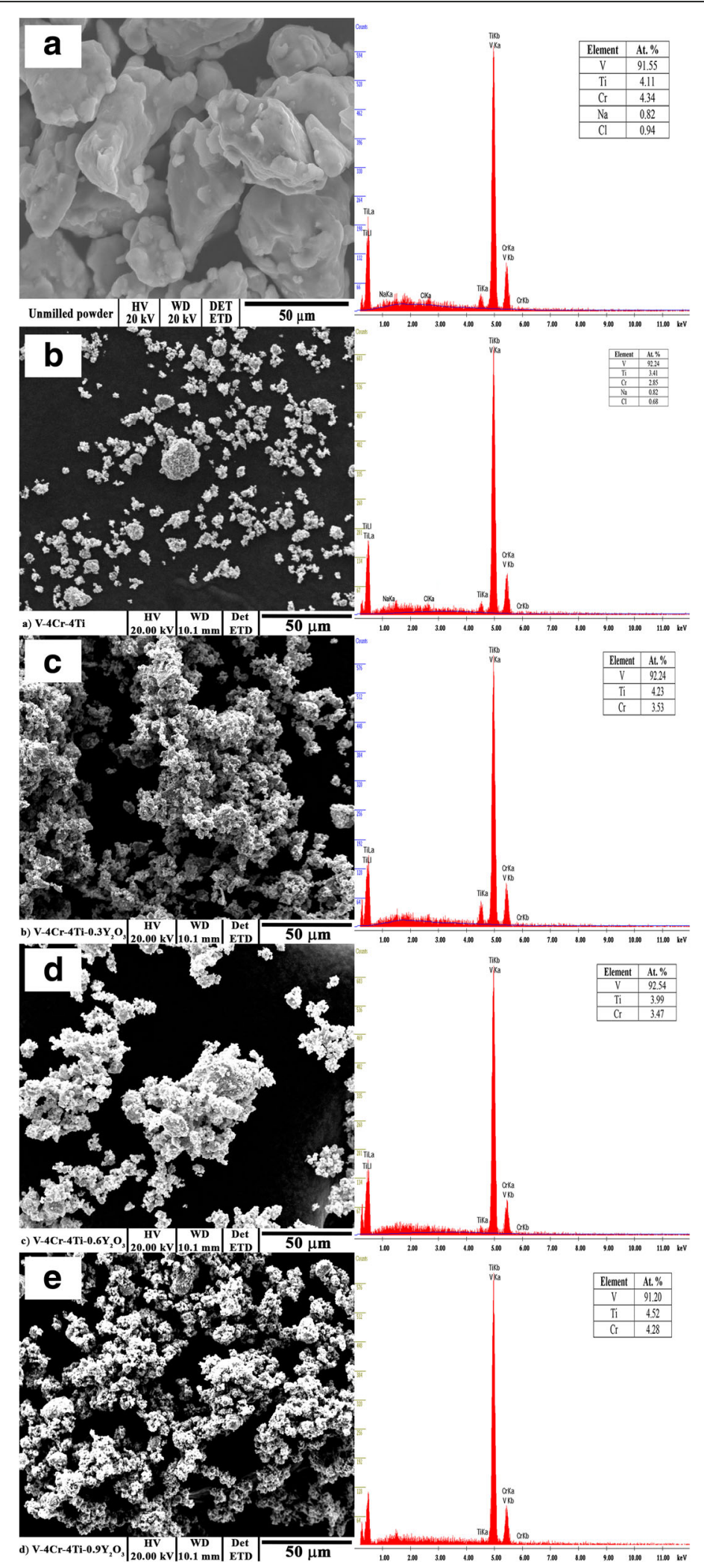

Fig. 1 Electron microscopy images accompanied with energy-dispersive absorptive spectroscopy patterns of a unmilled $\mathrm{V}-4 \mathrm{Cr}-4 \mathrm{Ti}$ powder, b milled $\mathrm{V}-4 \mathrm{Cr}-4 \mathrm{Ti}$ powder, and $\mathrm{V}-4 \mathrm{Cr}-4 \mathrm{Ti}$ powder ball-milled with varying yttria content: c $0.3 \%$ yttria, d $0.6 \%$ yttria, and e $0.9 \%$ yttria 


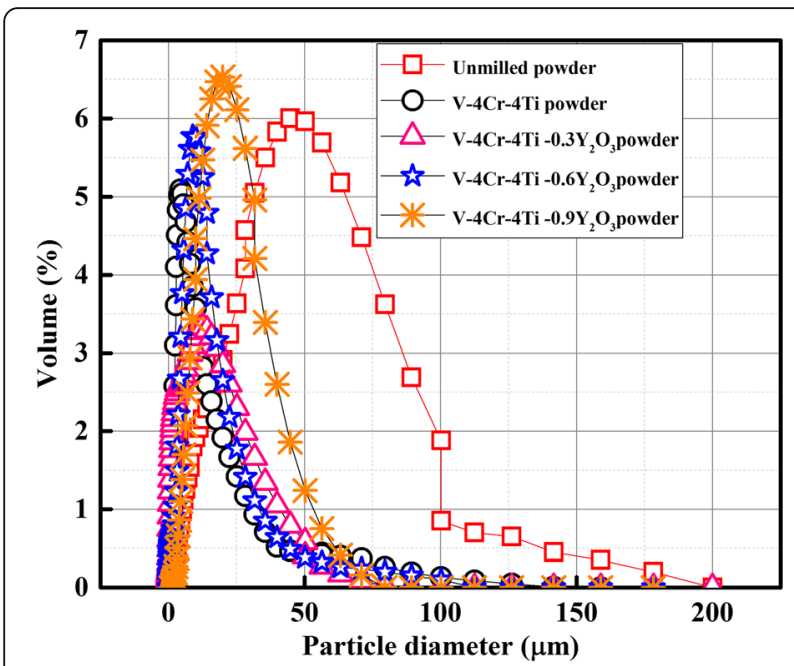

Fig. 2 Laser particle analysis of unmilled, milled, and yttria-dispersed $\mathrm{V}-4 \mathrm{Cr}-4 \mathrm{Ti}$ powders

with increasing yttria content (from 0.3 to 0.9 at.\%) clearly indicates the sluggish electromigration phenomenon across the individual powder particles (ODS vanadium powders) during sintering. Apart from the particle size and shape effect, yttria addition must have principally increased the population of metal-to-ceramic interfaces. Since the electrical conductivity across the metal-to-metal and the metal-to-ceramic interface is different altogether during sintering, the population of metal-to-ceramic interfaces could have possibly delayed (or suppressed) the subsequent stages of sintering, viz. spark discharge, formation of ionization column, vaporization, localized neck formation, plastic deformation, mass transport via ionization column (surface and volume diffusion), and solidification. Ascribed stages of sintering solely depend on the DC current conduction and its associated joule-heating phenomenon across the powders. Even if one stage gets delayed, overlapping of the subsequent stages of sintering can lead to poor sintering kinetics henceforth. The poorer the sintering kinetics, the lower will be the driving force for electromigration across the powders. If we compare the activation energy $\left(E_{\mathrm{a}}\right)$ values for DC

Table 2 Comparison of particle size outcomes obtained from the SEM and laser particle analysis

\begin{tabular}{lcc}
\hline Composition & $d_{\text {SEM }}(\mu \mathrm{m})$ & $d_{\mathrm{LPA}}(\mu \mathrm{m})$ \\
\hline Unmilled V-4Cr-4Ti powder & $40 \pm 15$ & $54 \pm 9$ \\
Milled V-4Cr-4Ti & $8 \pm 2$ & $12 \pm 2.4$ \\
V-4Cr-4Ti-0.3Y ${ }_{2} \mathrm{O}_{3}$ & $14 \pm 4$ & $15 \pm 1.4$ \\
V-4Cr-4Ti-0.6 $\mathrm{Y}_{2} \mathrm{O}_{3}$ & $19 \pm 7$ & $21 \pm 2.4$ \\
V-4Cr-4Ti-0.9Y ${ }_{2} \mathrm{O}_{3}$ & $24 \pm 8$ & $27 \pm 8.2$ \\
\hline
\end{tabular}

$d_{L P A}(\mu m)$ mean particle size measured using laser particle analyzer, $d_{\text {SEM }}(\mu \mathrm{m})$ mean particle size measured using scanning electron microscopy

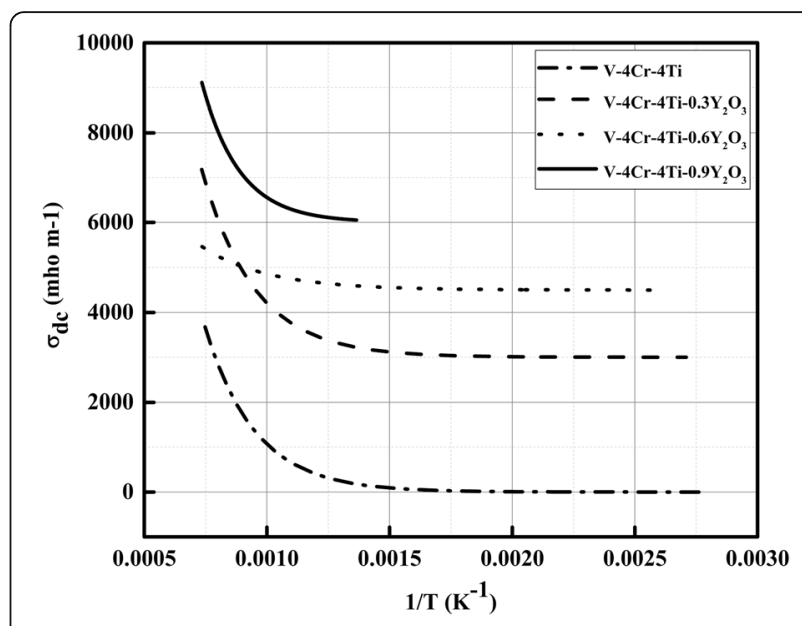

Fig. 3 DC conductivity profiles computed from the auxiliary data generated from the FAST setup while sintering $\mathrm{V}-4 \mathrm{Cr}-4 \mathrm{Ti}$ and yttria-dispersed $\mathrm{V}-4 \mathrm{Cr}-4 \mathrm{Ti}$ powders

current conduction of $\mathrm{V}-4 \mathrm{Cr}-4 \mathrm{Ti}(0.00084 \mathrm{eV})$ and $\mathrm{V}-$ $4 \mathrm{Cr}-4 \mathrm{Ti}-0.9 \mathrm{Y}_{2} \mathrm{O}_{3} \quad(0.034 \mathrm{eV})$ powders, by adding 0.9 at.\% of yttria in $\mathrm{V}-4 \mathrm{Cr}-4 \mathrm{Ti}$, the activation barrier required for DC current conduction across the powder particles has increased by 40 times. The solid line (see Fig. 4) indicating the activation energy profile of the $\mathrm{V}-4 \mathrm{Cr}-4 \mathrm{Ti}$ powder is relatively much steeper than the activation profiles of ODS vanadium powders. A steeper activation profile ( $\mathrm{V}-4 \mathrm{Cr}-4 \mathrm{Ti}$ powder) indicates excellent DC current conduction across the powder particles during sintering. On the other hand, when the yttria content is gradually increased from 0.3 to 0.9 at.\%, the activation profile becomes significantly flat indicating a higher activation barrier (or poor sintering kinetics). Even though the increase in yttria content has led to an inhomogeneous and larger particle size, the samples have achieved relative

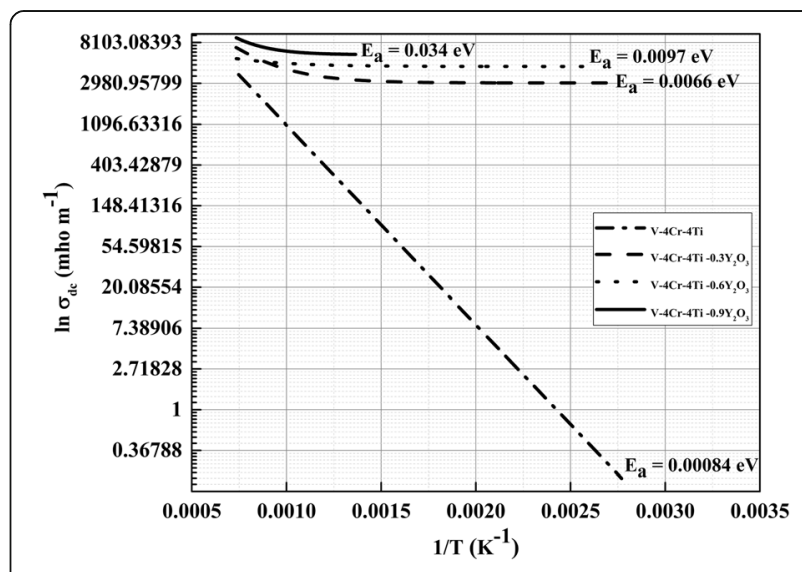

Fig. 4 Activation energy $\left(E_{a}\right)$ profiles of $\mathrm{V}-4 \mathrm{Cr}-4 \mathrm{Ti}$ and yttria-dispersed $\mathrm{V}-4 \mathrm{Cr}-4 \mathrm{Ti}$ powders depicting the suppression of sintering current (DC conductivity) as a function of varying yttria content in starting powders, during FAST process 
density close to the theoretical density with relatively lesser shrinkage/densification. The apparent relative densities of FAST-processed samples, viz. $\mathrm{V}-4 \mathrm{Cr}-4 \mathrm{Ti}$, $\mathrm{V}-4 \mathrm{Cr}-4 \mathrm{Ti}-0.3 \mathrm{Y}_{2} \mathrm{O}_{3}, \mathrm{~V}-4 \mathrm{Cr}-4 \mathrm{Ti}-0.6 \mathrm{Y}_{2} \mathrm{O}_{3}$, and $\mathrm{V}-4 \mathrm{Cr}-$ $4 \mathrm{Ti}-0.9 \mathrm{Y}_{2} \mathrm{O}_{3}$, sintered at identical sintering conditions are found to be $\sim 98 \%$.

\section{Conclusions}

$\mathrm{V}-4 \mathrm{Cr}-4 \mathrm{Ti}$ and yttria-dispersed $\mathrm{V}-4 \mathrm{Cr}-4 \mathrm{Ti}$ powders have been synthesized by ball-milling and consolidated using FAST process. Yttria addition has principally suppressed the surfactant's role as a process control agent during milling, resulting in powder agglomeration and the subsequent increase in the apparent particle size distribution. Electron microscopy imaging and laser particle size analysis of ball-milled powders do endorse the increase in the apparent particle size with varying yttria content in $\mathrm{V}-4 \mathrm{Cr}-4 \mathrm{Ti}$ powder. The steady increment in the apparent particle size distribution of ball-milled powders (with varying yttria content) has attributed an exponential increase in the current consumption during the FAST process. Hence, the magnitude of sintering current consumption (for sintering the discussed powders) during the FAST process can be seen as a function of yttria content in $\mathrm{V}-4 \mathrm{Cr}-4 \mathrm{Ti}$ powders. For the given sintering condition, FAST-processing of $\mathrm{V}-4 \mathrm{Cr}-4 \mathrm{Ti}$ powders consume a relatively low order of current when compared with its yttria-dispersed $\mathrm{V}-4 \mathrm{Cr}-4 \mathrm{Ti}$ counterpart. Activation energy values computed from the DC current conductivity profile also confirms the fact that yttria addition (0.3 to 0.9 at.\%) steadily increases the insulation resistance for DC current conductivity during FAST process.

\section{Highlights}

- Novel method developed for computing activation energy during sintering

- Effect of yttria-doping (in $\mathrm{V}-4 \mathrm{Cr}-4 \mathrm{Ti}$ ) on $\mathrm{DC}$ conductivity during sintering

- Yttria addition in $\mathrm{V}-4 \mathrm{Cr}-4 \mathrm{Ti}$ powder leads to powder agglomeration

- Powder characteristics affect dynamic current mobility during sintering

\begin{abstract}
Authors' contributions
VKK planned and carried out the experiments. VKK analyzed the metadata and generated the useful inferences presented in the manuscript. VKK drafted this manuscript along with SK. Significant efforts related to the proof-reading of the manuscript were done by SK along with VKK. The manuscript was uploaded by VKK, and the revisions will be attended by both the authors, collectively. Both authors read and approved the final manuscript.
\end{abstract}

\section{Competing interests}

The authors declare that they have no competing interests.

\section{Publisher's Note}

Springer Nature remains neutral with regard to jurisdictional claims in published maps and institutional affiliations.

Received: 3 June 2017 Accepted: 9 July 2017

Published online: 24 July 2017

References

Aalund, R. (2008). Spark plasma sintering. Ceramic Industry magazine. 158, 607610.

Adams, MJ. (1994). Agglomerate compression strength measurement test using a uniaxial confined. 78, 5-13.

Alamo, A, Regle, H, Pons, G, \& Béchade, JL (1992). Microstructure and textures of ODS ferritic alloys obtained by mechanical alloying. In Materials Science Forum (Vol. 88, pp. 183-190). Trans Tech Publications.

Anselmi-tamburini, U, Gennari, S, Garay, JE, \& Munir, ZA (2005). Fundamental investigations on the spark plasma sintering/synthesis process II. Modeling of current and temperature distributions. 394, 139-148.

Chen, W, Anselmi-Tamburini, U, Garay, JE, Groza, JR, \& Munir, ZA. (2005). Fundamental investigations on the spark plasma sintering/synthesis process. Materials Science and Engineering: A, 394(1-2), 132-138.

Chung, HM, Loomis, BA, \& Smith, DL (1996). Development and testing of vanadium alloys for fusion applications. 239, 139-156.

Gelles, DS (1998). Microstructural examination of irradiated $V \pm(4 \pm 5 \%) \mathrm{Cr} \pm(4 \pm$ 5\%) Ti. 263, 1380-1385.

limura, K, Suzuki, M, Hirota, M, \& Higashitani, K. (2009). Higashitani, Simulation of dispersion of agglomerates in gas phase - acceleration field and impact on cylindrical obstacle, Advanced Powder Technology, 20(2), 210-5.

Johnson, WR, \& Smith, JP (1998). Fabrication of a $1200 \mathrm{~kg}$ ingot of $\mathrm{V} \pm 4 \mathrm{Cr} \pm 4 \mathrm{Ti}$ alloy for the DIII $\pm \mathrm{D}$ radiative divertor program. 263, 1425-1430.

Krishnan, VK, Sinnaeruvadi, K, NU SC, RMHM (2016). http://www.sciencedirect. com/science/article/pii/S0263436815302900.

Loomis, BA, Chung, HM, Nowicki, LJ, \& Smith, DL (1994). !!!! I. 3115(94), 2-6.

Mamedov, V. (2000). Spark plasma sintering as advanced PM sintering method.

Miller, MK, Kenik, EA, Russell, KF, Heatherly, L, Hoelzer, DT, \& Maziasz, PJ (2003). Atom probe tomography of nanoscale particles in ODS ferritic alloys. 353, $140-145$.

Miller, MK, Hoelzer, DT, Kenik, EA, \& Russell, KF (2005). Stability of ferritic MA/ODS alloys at high temperatures. 13, 387-392.

Mills, PJT, Seville, JPK, Knight, PC, \& Adams, MJ (2000). The effect of binder viscosity on particle agglomeration in a low shear mixer agglomerator. 140147. http://www.sciencedirect.com/science/article/pii/S0032591000002242.

Mullier, MA, Seville, JPK, \& Adams, MJ (1991). The effect of agglomerate on attrition during processing. 65, 321-333.

Muroga, T, Nagasaka, T, Abe, K, Chernov, VM, Matsui, H, Smith, DL, Xu, ZY, \& Zinkle, SJ. (2002). Vanadium alloys - overview and recent results. Journal of Nuclear Materials, 307-311(1 SUPPL), 547-554.

Plant, CL, \& Steel, K (1995). Dispersion behaviour of oxide particles in mechanically alloyed ODS steel. 14, 1600-1603.

Rice, PM, \& Zinkle, SJ (1998). Temperature dependence of the radiation damage microstructure in $\mathrm{V} \pm 4 \mathrm{Cr} \pm 4 \mathrm{Ti}$ neutron irradiated to low dose. 263, 1414-1419.

Smith, DL, Chung, HM, Loomis, BA, Matsui, H, Votinov, S, Witzenburg, WV (1995). Fusion engineering and design development of vanadium-base alloys for fusion first-wall-blanket applications, 3796 (94).

Smith, DL, Chung, HM, \& Loomis, BA (1996). b ! fY, 15(96). http://www. sciencedirect.com/science/article/pii/S0022311596002310.

Suryanarayana, C, \& Norton, MG. (1999). Book review X-ray diffraction : a practical approach (pp. 13-15). https://books.google.co.in/books?hl=en\&lr=\&id= RRfrBwAAQBAJ\&oi=fnd\&pg=PA3\&dq=Xray+diffraction+:+a+practical +approach\&ots=NwGLKtau7e\&sig=jTAiYITe9dP0eJSA4-70K77jSmk\#v= onepage\&q=X-ray\%20diffraction\%20\%3A\%20a\%20practical\%20approach\&f= false.

Thornton, C. (1999). Numerical simulations of agglomerate impact breakage (pp. 74-82).

Thornton, C, Ciomocos, MT, \& Adams, MJ. (2004). Numerical simulations of diametrical compression tests on agglomerates. 140, 258-267.

Tong, ZB, Yang, RY, Yu, AB, Adi, S, \& Chan, HK. (2009). Numerical modelling of the breakage of loose agglomerates of fine particles. Powder Technology, 196(2), 213-221.

Yamagata, I, Kurishita, H, \& Kayano, H (1996). Development of oxide dispersion strengthened vanadium alloy and its properties. 239, 162-169. 
Yu, A. B., Bridgwater, J., \& Burbidge, A (1997). On the modelling of the packing of fine particles. Powder technology, 92 (3), 185-194.

Yu, AB, \& Standish, N (1993). Characterisation of non-spherical particles from their packing behaviour. 74, 205-213.

Yucheng, W, \& Zhengyi, F (2002). Study of temperature field in spark plasma sintering. 90, 34-37.

Zinkle, SJ, Matsui, H, Smith, DL, Rowcli, AF, Osch, EV, Abe, K, \& Kazakov, VA (2008). Research and development on vanadium alloys for fusion applications. 263, 205-214

\section{Submit your manuscript to a SpringerOpen ${ }^{\circ}$} journal and benefit from:

- Convenient online submission

Rigorous peer review

- Open access: articles freely available online

- High visibility within the field

- Retaining the copyright to your article

Submit your next manuscript at $>$ springeropen.com 